\title{
AINDA A REDESCOBERTA DE SÁ DE MIRANDA NO SÉCULO XX: CARLITO AZEVEDO E ALEXANDRE O'NEILL*
}

\author{
Márcia Maria de Arruda Franco \\ Universidade Federal de Ouro Preto - FAPEMIG
}

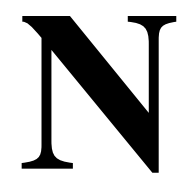

este ano 2000, em que se comemoram os 500 anos do Descobrimento do Brasil, é a poesia portuguesa, atual e antiga, que parece ter sido redescoberta, ao longo do século XX. Carlito Azevedo, poeta brasileiro ainda hoje vivo, em 1993, relê um dos mais bonitos decassílabos mirandinos, "E vou tresvaliando como em sonho”. Em 1979, Alexandre O'Neill dedicava um poema montado com versos de Mário de Sá Carneiro e Sá de Miranda a Augusto de Campos, que os "viu juntos" no anti-ensaio sobre Donne. Nas comemorações dos 500 anos, numa visão retrospectiva, é o passado quinhentista que está sendo redescoberto pelo presente, nos dois lados do Atlântico.

\section{Tresvariando como em sonho - a lírica amatória de Sá de Miranda e Carlito Azevedo}

Sá de Miranda e Carlito Azevedo. Entre esses poetas há uma distância histórica de mais ou menos cinco séculos. O primeiro nasceu ainda no século XV e por meados do XVI teria morrido. Introduziu em Portugal o decassílabo, as formas e os subgêneros líricos do Renascimento italiano, mas também continuou a usar a

* A presente versão deste trabalho não seria possível sem o subsídio de viagem fornecido pela Fundação Calouste Gulbenkian, em abril de 2000, para conclusão do projeto "Sá de Miranda, um poeta do século XX". 
medida velha. O outro é um poeta contemporâneo que com o seu livro de estréia Collapsus Linguae conquistou o Prêmio Jabuti- 92. Agora interessa-nos o seu segundo livro As Banhistas, o poema "Seixos Quentes", que cita, alterando, um verso do poeta quinhentista português Sá de Miranda, do soneto "Quando eu, senhora, em vós os olhos ponho".

Esse poeta pré-camoniano - da primeira metade do século XVI - desde os anos cinqüenta do século XX, vem sendo uma voz comunicante da poesia brasileira.

Como conseqüência do desafio lançado aos poetas das gerações anteriores pelos ideais estéticos da Geração de 45, a volta ao decassílabo e às formas renascentistas - introduzidos no idioma poético português por Sá de Miranda, no início da Idade Moderna - é justamente a voz desse Reformador da poesia portuguesa que passa a estar presente, a ser citada ou referida por uma constelação de poetas modernistas.

A primeira parte de Claro Enigma intitula-se "Entre Lobo e Cão", expressão que se reencontra no verso final de uma esparsa mirandina, "Não vejo o rosto a ninguém". O livro de Drummond é de 1951. Manuel Bandeira, em 1952, escreve "Elegia de Verão", que está em Opus 10, e é uma referência explícita ao mais afortunado dos sonetos mirandinos, "O sol é grande". Embora Drummond demonstre ter um conhecimento profundo da obra mirandina, e Augusto Meyer lhe dedique, nesses mesmos anos 50, dois ensaios, de fato, os impulsionadores do retorno à voz quinhentista de Sá de Miranda parecem ter sido os irmãos Campos. Antes do movimento concretista de 1956, em 1950-1951 e 1952, no início do Grupo "Noigandres", cada um fez a sua reverência a Sá de Miranda. Haroldo de Campos dedicou a parte 10 de "ciropédia ou a educação do príncipe" a este poeta que está na raiz do Idiomaterno e que merece ser admirado. Augusto de Campos retirou de um verso do soneto "Este retrato vosso é o sinal" o título de seu poema dedicado à lenda de Solange Sohl, "O sol por Natural", publicado pela primeira vez na revista Noigandres 1; em 1978, num texto crítico, aproxima o 
poeta português do trobar clus provençal; na introdução ao antiensaio sobre John Donne revê radicalmente as relações entre Camões e Sá de Miranda.

Para usar a linguagem dos irmãos Campos, Sá de Miranda se insere no paideuma ${ }^{1}$ da poesia brasileira da segunda metade desse século, isto é, no elenco de autores escolhidos pelo presente da criação para integrar a sua recolha da "tradição". A voz do poeta quinhentista passa a ser culturmorfológicamente atuante, ${ }^{2}$ passa a fazer parte da conformação da cultura poética presente. A fecundidade da voz mirandina no paideuma atual pode ser exemplificada por dois livros de poesia de 1993: o de Waly Salomão, Armarinho de Miudezas, e o de Carlito Azevedo.

Com a poética sincrônica foi possível uma revisão do sentido de tradição. Esta não é mais encarada como um conjunto estanque que passa de geração a geração, sem alterações, mas sim como um conjunto móvel que se organiza de acordo com os problemas de forma e conteúdo de cada geração e de cada poeta em particular.

Os poetas de determinada época, como leitores de poesia, citam determinados textos de poetas de outras épocas, lugares e línguas com que dialogam, ou porque são por eles influenciados, ou porque deles discordam: o que importa é que essas citações trazem no bojo uma vontade de dissociação entre o sentido antigo e o novo que se tenta cunhar. Esse é o movimento da intertextualidade, tão explorado na literatura do século XX.

É inegável que com a atividade literária, crítica e de tradução dos irmãos Campos foi possível uma renovação dos estudos literários brasileiros e portugueses. No entanto, ao considerarem que a poética sincrônica transforma poetas de tempos históricos distintos em contemporâneos, cometem um equívoco que já deu margem a críticas de que essa sincronia poética acabaria por descontextualizar

${ }^{1}$ CAMPOS et al. 1975. p.47.

${ }^{2}$ CAMPOS et al. 1975. p.47. 
de seu próprio tempo histórico a poesia do poeta antigo, lida anacronicamente. Já se entende agora que a poética sincrônica não transforma em poetas do mesmo tempo poetas de épocas diferentes, mas apenas promove a circulação histórica de procedimentos retóricos, que auxiliam os poetas do presente da criação na constituição do vínculo forma e conteúdo.

O objetivo aqui é surpreender a diferença de tempo histórico nas alterações promovidas pela citação do verso mirandino "e vou tresvaliando como em sonho", no poema de Carlito Azevedo, "Seixos Quentes", em que é transformado para "vais tresvariando/como em sonho para". São feitos três tipos de alterações. Substitui-se a forma antiquada tresvaliar pela atual tresvariar; muda-se a métrica do verso, o decassílabo é quebrado em dois versos de cinco sílabas e, por fim, muda-se a pessoa (da primeira para a segunda) do verbo tresvariar, que significa "dizer ou fazer desvarios, estar fora de si, delirar".

A primeira dessas alterações decorre de uma atualização morfológica, que revela uma diferença lingüística entre os séculos XVI e XX. A primeira forma quase desapareceu da língua (encontramo-la ainda em Camilo). A transformação do decassílabo nos quebrados de cinco sílabas assinala uma decisão pessoal do poeta contemporâneo, que escreve dentro de uma total liberdade de escolha rítmica, liberdade negada pelos pósteros a Sá de Miranda, cujos sonetos não têm o bom ritmo italiano, pois se compõem de decassílabos que nem sempre têm cesuras na sexta ou na quarta e oitava sílabas, mas seguem o ritmo anapéstico, com cesuras nas quarta e sétima sílabas, muito usado em versos medievais. Por fim, a última diferença vem lançar uma distinção fundamental entre a lírica amatória quinhentista e a contemporânea, o ato de tresvariar passa a se dar na sensibilidade da amada e não mais na subjetividade do poeta. Essas diferenças permitem que se façam aproximações e distanciamentos entre a lírica amatória quinhentista de Sá de Miranda e a lírica amatória contemporânea de Carlito Azevedo, reintegrandoas nos seus respectivos panoramas de época, e também estabelecendo conexões do ponto de vista poético. 
Mas para isso convém citar os dois poemas inteiros. E este soneto de Sá de Miranda tem o perfeito ritmo italiano.

Quando eu, senhora, em vós os olhos ponbo,

e vejo o que não vi nunca, nem cri

que houvesse cá, recolbe-se a alma a si

e vou tresvaliando, como em sonho.

Isto passado, quando me desponho, e me quero afirmar se foi assi,

pasmado e duvidoso do que vi,

m'espanto às vezes, outras m'avergonho.

Que, tornando ante vós, senhora, tal, quando m' era mister tant' outr' ajuda, de que me valerei, se alma não val?

Esperando por ela que me acuda, e não me acode, e está cuidando em al, afronta o coração, a língua é muda. ${ }^{3}$
SEIXOS QUENTES

(baigneuse)

1. Do mar, displicentes, caem seixos quentes

sobre o corpo da palavra desejo em vermelho, acesas, vagas, baralhadas, nuvens rasgam todo um céu leopardado:

2. Tudo isso - penso fias dentro quando, véspera de gozo, vais tresvariando como em sonbo para cima e para baixo, súbito então páras! pairas sobre as águas. ${ }^{4}$

À primeira vista, a subjetivação do objeto amado parece ser uma inovação da lírica amatória contemporânea, baseada numa diversa noção de moralidade. Mas essa diferença se dilui ao examinarmos outros poemas do poeta de quinhentos. Sá de Miranda de certa maneira escapa ao código cortês quinhentista quando apresenta variações significativas no tratamento do corpo e da subjetividade femininos. Num outro soneto, nos versos "E triste aquele vosso suspirar, / em que tanto mais vai", por exemplo, o suspiro é uma marca da subjetividade feminina, subjetividade que revela pelo

\footnotetext{
${ }^{3}$ MIRANDA, 1976. p.301.

${ }^{4}$ AZEVEDO, 1993. p.41.
} 
suspirar a presença do desejo, "em que tanto mais vai", o que era incomum na lírica de seu tempo. O corpo subjetivado da amada é imaginado para além do limite dos olhos. Tenta-se relacionar o "fiar dentro" da amada com a graça exterior do seu retrato, por exemplo, nos versos finais de outro soneto "que a graça em vós não morre em nenhüa hora. / Falando que fará? Que fará rindo?”. O retrato da subjetividade feminina culta e casta construído por Miranda ainda pode ser lido na "Elegia a uma senhora muito lida em nome de um seu servidor", ou em Encantamento, com Inês dando lições de poesia e amor ao sobrinho e afilhado. ${ }^{5} \mathrm{Na}$ elegia, reutilizando as imagens do tresvariar como em sonbo e do suspirar, o poeta teme pelo resultado da "busca" pela interioridade em sua relação com a senhora, "a vã Eco", a que repete em vão o suspiro amoroso: "Que sorte tam estranha de peçonha! / Ando em busca de mim não sei por onde, / em quanto esta alma tresvalia e sonha. / Aqui somente a vã Eco responde, / Que parece também que and'ela em busca, / não sei per que cavernas se m'esconde. / Quando o mundo esclarece, e quando embrusca, / suspirando eu, suspira, ah! crueldade! / também dirá por mim: este que busca?". A subjectivação do objecto amado parece mais uma novidade da lírica de Sá de Miranda.

Carlito Azevedo, por sua vez, reabilita o serviço amoroso e a figura da musa, presentes em sua obra desde o primeiro livro: "uma colhedora de mimosas a que um / homenzinho cedesse a passagem / à espera (desesperada) / de um sorriso". Mas o cortejar do poeta não se pauta pelo código cortês quinhentista, estando comprometido com a prática amorosa de sua época, em que uma moralidade menos severa permite que se façam versos sobre a palavra desejo e o gozo feminino.

A subjetivação do objecto amado não distingue essas duas visões do lirismo amoroso; a possibilidade de se descrever o êxtase sexual feminino, sim. No entanto não nos podemos apressar e dizer que no soneto mirandino há uma ausência do corpo, há antes uma

${ }^{5}$ MACEDO, 1998. p.221. 
ignorância de como usá-lo. A separação do sujeito em corpo e alma gerava um estado de conflito no eu-amoroso: "Me espanto às vezes, outras m' avergonho". O poeta, como na epígrafe mirandina de Waly Salomão, se encontra "repartido entre extremos, que não entend[e]", isto é, neste soneto, "pasmado e duvidoso do que vi[u]". No poema de Carlito Azevedo, o gozo é descrito sem culpas, sem vergonhas, do ponto de vista feminino. O tresvariar, embora pensado pelo poeta, é o da amada e não o do amante. A novidade de Carlito está em se referir a esse corpo subjetivado no seu estado de tresvario e não no de suspiro. Há realização do Amor através do corpo da amada, há um contato físico e não apenas a realização sublimada pelo tresvariar da mente do poeta, após a visão da amada, conduta comum na lírica amatória quinhentista, glosada pelo soneto de Miranda, onde com a "alma recolhida", o corpo do poeta se vê "mudo e afrontado" pela presença do corpo amado. Com a fuga da alma, o sujeito poético não sabe como valorizar o corpo. A língua é muda para dizer o desejo, conhecido tópico do lirismo amoroso provençal. No entanto, em Sá de Miranda, o contato visual com o corpo da amada é fundamental para a experiência do tresvario. No segundo quarteto, fora da presença do corpo feminino, a disposição do poeta em se lembrar da sensação provocada pela presença feminina não consegue repetir o tresvariar, e são instaurados o espanto e a vergonha, o pasmo e a dúvida.

Essa diversa circulação do corpo na relação amorosa é efeito de diferenças históricas: o modo como o amante se comporta diante do corpo da amada, e sinaliza, na citação do texto antigo, a distância de valores entre a sociedade quinhentista e a atual. E essa a novidade é justamente trazida pela alteração do sujeito do verbo tresvariar.

Tal diferença no tratamento do corpo amado é reforçada pela primeira parte do poema "Seixos quentes". Ao citar o verso mirandino, na segunda parte, o poema de Carlito Azevedo não o descontextualiza de sua historicidade; ao contrário, através das alterações, morfológica, métrica e de pessoa, marca a distância temporal entre a lírica amatória quinhentista e a contemporânea, 
promovendo a liberação do corpo da palavra desejo, da própria musa, ou baigneuse.

A perspectiva da poética sincrônica não torna contemporâneos Sá de Miranda e Carlito Azevedo, mas permite que entre eles se estabeleçam diferenças históricas e semelhanças de procedimentos retóricos. Os dois se inscrevem dentro da lírica amatória e os dois subjectivam o objecto amado. Mas há uma diferente moralidade que, historicamente localizada, preside o encontro amoroso.

Além do lirismo amoroso há outras semelhança de atitude poética, como, por exemplo, o fato de considerarem a composição poética como ars isto é, como técnica, "desconfiando do estalo", como no poema "Da Inspiração", de Collapsus Linguae, da fúria da primeira inspiração, diria Rodrigues Lapa. Para Jorge de Sena, Sá de Miranda era um "torturado da forma" nos dois sentidos, antigo e moderno: no de reescrever constantemente e no de cortar o supérfluo. Em suma, a voz quinhentista de Sá de Miranda participa, na moderna poesia brasileira, do presente da criação, marcando a sua diferença histórica e sugerindo procedimentos retóricos para o lirismo amoroso, a partir da imagem do tresvariar como em sonho.

\section{O mito do "imigo de si" no "Sá de Miranda Carneiro", de Alexandre O'Neill}

No limiar dos Tempos Modernos, tem início, na poesia portuguesa, o questionamento do sujeito-poeta como aquele que trava uma luta constante consigo mesmo. O tema, que se precipita no ciclo quinhentista do "imigo de si", será retomado, em 1979, por Alexandre O'Neill, no poema-montagem intitulado "Sá de Miranda Carneiro". ${ }^{6}$ A montagem com versos alternados da primeira quadra de "Comigo me desavim" e do "7" 7 aproxima-se do modo torturado

${ }^{6}$ O’NEILL, 1979. p.13. 
da escrita mirandina, que pode ser encarada como uma remontagem de textos, e aponta para a permanência, em Sá Carneiro, do questiona-mento do sujeito como "imigo de si". Em relação ao próprio O’Neill, cabe ressaltar que não há uma vivência subjetiva deste conflito, mas que está em jogo apenas uma desconstrução vanguardista dos mitos do imaginário poético português, escrita menos na "seqüência" de Jorge de Sena, que compôs um "Sá Soares de Miranda de Passos", nove anos antes, do que na de Augusto de Campos, a quem a montagem é dedicada porque "viu juntos" os dois Sás, compondo o seu "sá de miranda carneiro", um ano antes do de O’Neill. Antes de entraramos nesta empresa poética luso-brasileira, vamos falar um pouco da história desse tema na poesia ibérica na passagem do século XV para o XVI.

A herança hispânica fornece este tópico com a cantiga de Jorge Manrique "No se por que me fatigo", glosada por Sá de Miranda. As Glosas mirandinas, editadas pela primeira vez no Cancioneiro de Resende, abrem a edição novecentista de Rodrigues Lapa das Obras Completas de Sá de Miranda; o primeiro verso que se lê é o de Manrique. O processo criativo da glosa consiste em terminar cada uma de suas "voltas" com um verso do mote. Este esquema é tecido por Sá de Miranda em cima da cantiga inteira de Manrique, tomada como um mote de doze versos. É no pórtico das obras mirandinas que a passagem da lírica amatória para a reflexiva se processa, e em castelhano.

Lo más como lo sabré?

Que en aquel punto ordenado

que a vos los ojos alcé,

a mi desamado me he

y vos a mi desamado?

7 MIRANDA, 1976. v.1, p.9-10.

8 SÁ-CARNEIRO, 1980. p.47.

${ }^{9}$ MIRANDA, 1976. v.1, p.4. 
Da rendição ao amor (à amada) chega-se à inimizade entre o sujeito e si mesmo, o que gera a loucura e a solidão:

Todos van al su provecho;

yo, que a mis males me obligo, ando comigo en despecho;

de tan duro y cruel pecho

quien osará ser amigo?

Mas, qué digo yo? Osará, y no mucho, antes ansí:

qual peligro deterná aquel que fuyendo vá del enemigo de si? ${ }^{10}$

No final da glosa da cantiga de Manrique, Sá de Miranda chega à conclusão de que o "enemigo de si" provoca a sua própria ruína, fazendo com que as pessoas fujam dele.

O tema teve grande fortuna na poesia quinhentista portuguesa em medida velha, sendo glosado por Bernardim Ribeiro, no vilancete "Entre mim e mim mesmo", e por Camões, na cantiga "De que me serve fugir". ${ }^{11}$ Ele reaparece em muitas trovas mirandinas, como, por exemplo, numa cantiga de que se conhecem três versões. Ao confrontá-las, o interprete se dá conta de que há um deslizamento do campo da lírica amatória para o campo da lírica reflexiva, feito a partir da reorganização de alguns versos.

Aqui nos interessa a montagem de O'Neill. Por isso vejamos logo as duas versões mais conhecidas de "Comigo me desavim", pois exemplificam a depuração do trabalho criativo mirandino:

Comigo me desavim, sou posto em todo perigo;

não posso viver comigo nem posso fugir de mim.

${ }^{10}$ MIRANDA, 1976. v.1, p.5-6.

${ }^{11}$ BERARDINELLI, 1973. p.74-7. 
Com dor, da gente fugia, antes que esta assi crecesse;

agora já fugiria de mim, se de mim pudesse. Que meo espero ou que fim do vão trabalho que sigo, pois que trago a mim comigo, tamanho imigo de mim? ${ }^{12}$

A versão de 1595, posterior à do Cancioneiro de Resende, de 1516, traz algumas lições diversas, substituindo, como se pode acima constatar, o verso 2: "vejo-me em grande perigo" por "sou posto em todo perigo", em que o sujeito ativo capaz de ver a si mesmo é substituído por um sujeito passivo, incapaz de controlar o seu estado; os versos 5 e 6: "antes qu'este mal tevesse / da outra gente fugia;" por "Com dor, da gente fugia / antes que esta assi crecesse". Nesta mudança há não só uma alteração de sentido (o sujeito sempre teve o mal da dor, na versão de 1595), mas sobretudo é sinalizado um procedimento típico da "tortura da forma" mirandina em busca da expressão poética mais condensada: os versos (5 e 6) da versão de 1516 são sintetizados num único verso (5) da versão posterior, que traz um alargamento do sentido, isto é uma reflexão sobre o crescimento da dor. Ainda são trocadas algumas palavras dos versos 9 e 10: "cabo" por "meo" e "deste cuidado" por "do vão trabalho". A última substituição pode ser lida como uma tentativa de explicitar a atividade do poeta. O "cuidado", visto como "trabalho", não pertence à esfera lírico-amorosa (não é mera tradução da "cuita"), e sim pertence à esfera auto-reflexiva, por assim dizer, metapoética da pena mirandina. Ao substituir a acepção reflexiva da palavra cuidado pela palavra trabalho o poeta deixa clara uma reflexão sobre a escrita do poético. A compreensão da atividade poética como um trabalho com a forma aproxima a poética mirandina da contemporaneidade. Por sua vez, a aproximação entre Sá de Miranda e SáCarneiro se concentra no tema do "imigo de si".

${ }^{12}$ MIRANDA, 1976. v.1, p.9-10. 
Examinemos, rapidamente, a disseminação do tema do "7" na obra de Sá-Carneiro:

Eu não sou eu nem sou o outro, Sou qualquer coisa de intermédio:

Pilar da ponte de tédio

Que vai de mim para o Outro ${ }^{13}$

Este pequeno poema é um dos mais característicos da "poética doente"14 de Sá-Carneiro, estruturada sobre o tema da cisão subjetiva. Os poemas de Dispersão, escritos entre fevereiro e maio de 1913, podem ser lidos como uma longa glosa do tema do "imigo de si". Em "Escavação”, o próprio eu é objeto de uma procura: "Divago por mim mesmo a procurar / desço-me todo, em vão, sem nada achar", "Onde existo que não existo em mim?". ${ }^{15}$ Em "Álcool", o sujeito em busca de si encontra a dissipação: "Quero reunir-me, e todo me dissipo", "Corro em volta de mim sem me encontrar...". ${ }^{16}$ Reconhece o egocentrismo como autor da auto-maldição: "Que sortilégio a mim próprio lancei?", "É só de mim que ando delirante". ${ }^{17}$ Em "A queda", a batalha consigo mesmo é vencida pelo autoaniquilamento: "Não me pude vencer, mas posso me esmagar, / Vencer às vezes é o mesmo que tombar -", "E fico só esmagado sobre mim!" ${ }^{18}$ Por fim, a morte é a "dispersão total" daquele que não era "amigo de ninguém". ${ }^{19}$

A dispersão do sujeito aparece tanto nas novelas, através dos trios amorosos, ${ }^{20}$ como nas cartas a Fernando Pessoa, onde rompe as fronteiras entre biografia e discurso poético, ao assumir, para além

\footnotetext{
13 SÁ-CARNEIRO, 1980. p.47.

${ }^{14}$ JÚDICE, 1990. p.9.

15 SÁ-CARNEIRO, 1980. p.14.

16 SÁ-CARNEIRO, 1980. p.17.

17 SÁ-CARNEIRO, 1980. p.18.

18 SÁ-CARNEIRO, 1980. p.34.

19 SÁ-CARNEIRO, 1980. p.21.

${ }^{20}$ MACHADO, 1994. p.145-149.
} 
de um questionamento ontológico, característico da poética pessoana, a conotação de conflito psicológico. Compare-se o desencontro consigo mesmo através da busca de si pela imagem do espelho, neste trecho de "Dispersão": "Não sinto o espaço em que encerro / Nem as linhas que projeto: / Se me olho em um espelho, erro / - Não me acho no que projeto"; ${ }^{21}$ e neste da carta de 13 de maio de 1913 a Fernando Pessoa:

Quantas vezes em frente dum espelho - e isto já em criança - eu não perguntava olhando a minha imagem: "Mas o que é ser-se eu; o que sou eu? "E sempre, nestas ocasiões, de súbito, me desconhecia, não acreditando que eu fosse eu, tendo a sensação de sair de mim próprio. Conhece isto? ${ }^{22}$

$\mathrm{Na}$ medida em que também está disseminado pela obra pessoana, o tema do vazio e desencontro subjetivos, da inimizade consigo mesmo, aproxima ainda mais os dois amigos de Orfeu. Como Sá-Carneiro "[pressente] um grande intervalo", ${ }^{23}$ Fernando Pessoa, lembrando Bernardim Ribeiro, elucida: "Sou entre mim e mim o intervalo". ${ }^{24}$ No famoso poema de Pessoa dedicado "A SáCarneiro" a imagem do vazio gerado pela dispersão subjetiva retorna às avessas: "hoje, falho de ti, sou dois a sós", "Como éramos só um falando! Nós / Éramos como um diálogo numa alma". ${ }^{25}$ O paralelismo na busca do eu entre os dois poetas revela-se nestes versos de Pessoa: "Aí onde escrevestes aqueles versos / Do trapezio, doriunos", ${ }^{26}$ em que, provavelmente, se refere aos versos de Sá-Carneiro do "16": "(Subo por mim acima como por uma escada de corda, / E a minha Ânsia é um trapézio escangalhado...)". ${ }^{27}$

\footnotetext{
${ }^{21}$ SÁ-CARNEIRO, 1980. p.20.

22 SÁ-CARNEIRO, 1978. p.62-3.

23 SÁ-CARNEIRO, 1980. p.16.

${ }^{24}$ PESSOA, 1981. p.93.

25 PESSOA, 1981. p.185.

${ }^{26}$ PESSOA, 1981. p.185.

${ }^{27}$ SÁ-CARNEIRO, 1980. p.45.
} 
A amizade dos dois poetas era um remédio para o estado de doença subjetiva. Na carta de 2 de dezembro de 1912, Sá-Carneiro afirmava o estado de beatitude advindo da comunhão com Pessoa: "E depois a sua carta confortou-me. Porque a sua carta define maravilhosamente aquilo que eu sinto. É o médico expondo ao cliente toda a engrenagem minuciosa da sua enfermidade". ${ }^{28}$ Numa das últimas cartas de Sá-Carneiro a Pessoa, retomando a mesma imagem do verso de Sá de Miranda, "Sou posto em todo perigo", que na edição de 1885, de Carolina Michaëlis de Vasconcelos, aparece com a lição "No estremo som [sou] do perigo", ${ }^{29}$ o suicida, como uma das suas personagens, "atinge todo o perigo." 30

Antes de analisar a montagem de O' Neill é preciso comentar a dedicatória a Augusto de Campos. Entre os poetas do Brasil e de Portugal, ao longo do século XX, houve um diálogo experimentalista, que, tendo um pé na figura de Sá de Miranda, recuperado, aqui e lá, por conta da concisão de sua linguagem, resultou em reverência de alguns poetas portugueses, como Carlos de Oliveira e Jorge de Sena, aos poetas modernistas brasileiros, tais como Manuel Bandeira, Drummond, João Cabral de Melo Neto e os irmãos Campos. O'Neill, poeta que saúda o prosaico João Cabral, ${ }^{31}$ deixando entrever em alguns poemas a busca da maneira cabralina de poetar, em "Formas da violência", inverte o famoso verso de Bandeira: "Macaquear, ainda que por olvidada ancestralidade colonialista, o falar dos Brasileiros".32

Augusto de Campos viu juntos Sá de Miranda e Sá-Carneiro em "John Donne: o dom e a danação", anti-ensaio de 1978, publicado pela Noa-Noa, e depois em 1986 n'O Anticrítico. Retirando os dois Sás para fora da "tradição de tagarelas" da literatura portuguesa,

\footnotetext{
28 SÁ-CARNEIRO, 1978. p.33.

${ }^{29}$ VASCONCELOS, 1885.

30 SÁ-CARNEIRO, 1979. p.182.

${ }^{31}$ O'NEILL, 1984. p.163.

32 O'NEILL, 1984. p.375.
} 
Augusto monta uma cantiga com duas quadras de "Comigo me desavim", intermediadas pela primeira quadra de "Dispersão": "Perdime dentro de mim / Porque eu era labirinto, / E hoje, quando me sinto, / É com saudades de mim.", fornecendo o título da montagem de O’Neill: "sá (de miranda) carneiro". Talvez por citar de memória, o terceiro verso de "Dispersão" (onde é "E hoje" põe "agora") e alguns versos da cantiga de Sá de Miranda são alterados pelo anticrítico concreto: no segundo, troca "sou posto" por "fui posto"; no quarto, "nem" por "não", e no nono, ao invés da forma arcaica "meo", usa a atual "meio". Acredito que se trata de falha da memória, pois, de olhos abertos para o significante arcaico, Augusto aproxima os dois poetas dos jogos de linguagem da lírica maneirista: a forma arcaica da palavra amigo, "imigo", é analisada como "anti-migo, imigo, onde a paranomásia com comigo / reetimologiza a palavra / "pronome em lugar do nome" / imigo, o inimigo em mim", ${ }^{33}$ sintetizando a glosa de Camões ao tema, "Que eu mesmo sou o meu perigo". Nesse anti-ensaio Augusto considera que, perto de Miranda, "até Camões é palavroso". ${ }^{34}$ Curiosamente, e assinalando a glosa seiscentista do tema, o dístico inicial de "Dispersão" aproxima-se, sintática e imagéticamente, dum dístico de Martim de Castro do Rio, poeta maneirista pouco conhecido, citado por Vitor Manuel de Aguiar e Silva: "Perdime dentro em mim como em deserto / Minh[a] alma está metida em laberinto".35

No século XVI, o tema do "imigo de si" fez parte da redescoberta renascentista da subjetividade. Deslizando da lírica amatória para a reflexiva, o tema indicia, entre os poetas quinhentistas que o glosaram, o caráter sui generis do sujeito poético português como o que conhece a loucura de não gostar de si mesmo. No século XVII, amaneiriza-se o conflito labiríntico do eu-poético. Em Sá-Carneiro, a cisão subjetiva atinge um nível trágico de dilaceramento psicológico, levando o poeta ao suicídio. A montagem de O'Neill, por sua vez,

33 CAMPOS, 1986. p.40.

${ }^{34}$ CAMPOS, 1986. p.39.

35 SILVA, 1971. p.247-8. 
aponta para uma dimensão outra do tema, em que são repensados os pressupostos tradicionais do lirismo reflexivo português: o sujeitopoeta, diante da irrealização amorosa ou da busca de si mesmo, não enlouquece, nem se suicida, mas brinca, joga, monta:

Sá de Miranda Carneiro

A Augusto de Campos, que os viu juntos.

comigo me desavim

eu não sou eu nem sou o outro

sou posto em todo o perigo

sou qualquer coisa de intermédio

não posso viver comigo

pilar da ponte de tédio

não posso viver sem mim

que vai de mim para o Outro ${ }^{36}$

Aqui se evidencia a recusa da poética experimental de O'Neill em resguardar os lugares-comuns da poesia portuguesa. Esta recusa e a atitude experimentalista podem ser reencontradas na figura de Sá de Miranda, o Reformador da poesia medieval portuguesa. O tema do "imigo de si" é visto sob um prisma lúdico: o que permite uma visão distanciada deste tópico recorrente na poesia portuguesa. Maria Antónia Oliveira, jovem exegeta de O’Neill, salienta que:

A solução para escapar a esta atitude de impotência decadente e sombria é a paixão pelo lúdico. O’Neill faz da sua amargura um jogo. O jogo poupa o ego - irresponsabiliza-o, brinca com o sério; jogarse é colocar-se fora do tempo." ${ }^{37}$

Podemos aproximar esta "paixão pelo lúdico" do "amor desigual" de Sá de Miranda pela leitura e pela escritura, atividades que driblam o "enfado aldeão", como se pode ver na Carta a Mem de Sá: "àquelas letras que sigo / devo que nunca me enfado". ${ }^{38}$

\footnotetext{
${ }^{36}$ O'NEILL, 1979. p.13.

37 OLIVEIRA, 1992. p.55.

${ }^{38}$ MIRANDA, 1977. p.74.
} 
Segundo E. M. de Melo e Castro, O'Neill "escapa ao spell pessoano por não ser assimilável ao "novo caminho de ferro que vai de Antero a Pascoais e se prolonga até ao Supra Camões"39 e por estar inscrito em outro projeto: "o da poesia jocosa e arcádica do século XVIII." ${ }^{40}$ Oposto ao projeto do Pessoa de Mensagem "que tem como referentes os grandes mitos nacionais e a construção de um sistema fechado de onde dimanam centrifugamente os valores do futuro" ${ }^{41}$ o projeto experimental, de que participa O'Neill, "tem por referentes a materialidade da comunicação que constitui um sistema aberto" (Ibidem), como o que apontamos na montagem de "Sá de Miranda Carneiro". A seriedade do mito do "imigo de si", definidora de um modo de ser português: aquele que se auto-rejeita e se compraz no sofrimento, na pena de O' Neill, é ironizada, através de um jogo com a lógica sintático-semântica da citação.

O último verso da quadra mirandina que serve à montagem de O'Neill não é "Nem posso fugir de mim", como está nas versões conhecidas de "Comigo me desavim" e sim "Não posso viver sem mim". Parece-me que esta alteração não é do mesmo tipo das acima apontadas na montagem de Augusto de Campos. A alteração proposta por O'Neill estabelece um paralelismo com o verso anterior "Não posso viver comigo", que, de certa forma, banaliza o conflito subjetivo, tornando-o um óbvio dilema: "Não posso viver comigo / Não posso viver sem mim". É justamente neste verso que a lógica sintático-semântica da montagem provoca um estranhamento: "Não posso viver sem mim / que vai de mim para o Outro". Gramaticalmente correto seria dizer: "Não posso viver sem mim / que vou de mim para o Outro". O sentido do dístico poderia ser o de que o eu não pode viver sem o "mim", "pilar da ponte" para ir ao Outro. Então há uma lógica semântica no dístico da montagem: o mim, tão longe do eu, é já um ele, ou ela: "aquela parte de mim que vai de mim para

\footnotetext{
${ }^{39}$ CASTRO, 1984. p.51.

${ }^{40}$ CASTRO, 1984. p.51.

${ }^{41}$ CASTRO, 1984. p.54.
} 
o Outro sem a qual não posso viver e da qual não posso fugir, segundo a lição de Sá de Miranda.

A modificação do quarto verso de "Comigo me desavim" deve ser encarada como um afrouxamento proposital da linguagem, isto é, do trabalho da citação. É mais uma tentativa de desconstruir, seja pela banalização do sério, seja pelo experimentalismo vanguardista com a linguagem, os mitos histórico-literários portugueses, conforme justificação do próprio O’Neill em "Bom e Expressivo": "Acaba mal o teu verso / mas fá-lo com um desígnio / é um mal que não é mal / é lutar contra o bonito". ${ }^{42}$

Dentro do programa de parodiar o imaginário consagrado português, o questionamento do mito do "imigo de si" também se evidencia no poema intitulado "Amigo". ${ }^{43}$ Ao lado de versos que recorrem a "clichês" sobre a amizade: "”Amigo" é um sorriso/ (...) um olhar bem limpo, / Uma casa, mesmo modesta, que se oferece, (...) "Amigo" é a solidão derrotada", O’Neill, na medida em que o "imigo de si" é o que não é "amigo de ninguém”, ou só dos que também são "imigos de si", aqueles de quem as pessoas "fogem", restabelece a amizade como um valor de relação inter-humana: "Amigo" (recordamse vocês aí, / Escrupulosos detritos?) / "Amigo" é o contrário de inimigo! / "Amigo" é o erro corrigido, / Não o erro perseguido, explorado, / É a verdade partilhada, praticada." Ao invés da loucura, do suicídio e do "gosto de ser triste", temas ou erros tradicionais do lirismo reflexivo português, O’Neill propõe: “'Amigo’ vai ser, é já uma grande festa!”.

Com este poema O'Neill concretiza um diálogo poético lusobrasileiro em torno da poética antiga de Sá de Miranda. De fato, tanto a releitura de Carlito Azevedo como a de O`Neill derivam da redescoberta de Sá de Miranda propiciada pelos irmãos Campos, que em sua atividade crítica, poética e de tradução sempre se referem ao poeta pré-camoniano como voz significante para a criação poética novecentista em língua portuguesa.

${ }^{42}$ O'NEILL, 1984. p.218.

${ }^{43}$ O'NEILL, 1984. p.90. 


\section{Referências Bibliográficas}

AZEVEDO, Carlito. Collapsus linguae. Rio de Janeiro: Lynx, 1991.

AZEVEDO, Carlito. Seixos Quentes. In: As banhistas. Rio de Janeiro: Imago, 1993

BABILLOD, Françoise. L'éclogue de l'énchantement de Sá de Miranda, Biblos, XII, Coimbra, p.573-579, 1963.

BERARDINELLI, Cleonice. A dimensão tradicional da lírica camoniana. In: Estudos Camonianos. Rio de Janeiro: MEC, 1973. p.55-81.

CAMPOS, Augusto. John Donne: o dom e a danação. In: O Anticrítico. São Paulo: Companhia das Letras, 1986. p.39-43.

CAMPOS, Haroldo. Poética sincrónica. In: A arte no borizonte do provável. São Paulo: Perspectiva, 1969.

CAMPOS, Haroldo et alli. Teoria da poesia concreta. 2.ed. São Paulo: Duas Cidades, 1975.

CASTRO, E. M. de Melo. A herança de Pessoa ou a vida e a morte textual de D. Sebastião. Literatura Portuguesa de Invenção. São Paulo: Difel, 1984. p.41-57.

COMPAGNON, Antoine. La seconde main ou le travail de la citation. Paris: Seuil, 1979.

COMPAGNON, Antoine. O trabalho da citação. Belo Horizonte: UFMG, 1996.

JÚDICE, Nuno. Prefácio a SÁ-CARNEIRO, Mário. Poesia. s. 1.: Círculo de Leitores, 1990. p.9-17.

MACEDO, Helder \& GIL, Fernando. Sá de Miranda e as ambigüidades do conhecimento. In: Viagem do olhar. Retrospecção, visão e profecia no Renascimento português. Porto: Campo das Letras, 1998.

MACHADO, Lino. Inter-relações: A confissão de Lúcio e outros textos de Sá-Carneiro. In: Semana de Estudos de Mário de Sá-Carneiro, Centro de Estudos Portugueses, 1994, Anais... Belo Horizonte: FALE/UFMG, 1994. p.144-150.

OLIVEIRA, Maria Antónia. A tristeza contentinha de Alexandre O’Neill. Lisboa: Caminho, 1992.

O’NEILL, Alexandre. A saca de orelhas. Lisboa: Sá da Costa, 1979. 
O'NEILL, Alexandre. Poesias Completas. Lisboa: IN-CM, 1984.

PESSOA, Fernando. Poesias Inéditas (1930-1935). Lisboa: Ática, 1981.

SÁ-CARNEIRO, Mário de. Cartas a Fernando Pessoa. Lisboa: Ática, 1978-1979. 2 vols.

SÁ-CARNEIRO, Mário de. Poesias. Lisboa: Ática, 1978.

SÁ-CARNEIRO, Mário de. Poesias completas. Porto: Anagrama, 1980.

SÁ DE MIRANDA, Francisco de. Obras completas. Lisboa: Sá da Costa, 1976-1977. 2 vols.

SENA, Jorge de. a) A viagem de Itália. e b) Reflexões sobre Sá de Miranda, ou a arte de ser moderno em Portugal. In: Estudos de Literatura Portuguesa I. Lisboa: Edições 70, 1981. p.49-67.

SILVA, Vitor Manuel de Aguiar e. A temática da lírica maneirista. In: Maneirismo e Barroco na poesia lírica portuguesa. Coimbra: Centro de Estudos Românicos, 1971. p.221-323.

\section{Resumo}

Na segunda metade do século XX, a poesia de Sá de Miranda foi redescoberta por alguns poetas da língua portuguesa, nos dois lados do Atlântico. Aqui apresentamos dois exemplos desta redescoberta, o de Carlito Azevedo, nos anos noventa, no Brasil, e o de Alexandre O'Neill, nos anos setenta, em Portugal. Ambos parecem redescobrir a atualidade do poeta antigo através dos irmãos Campos.

\section{Abstract}

On the second half of the XXth century, Sá de Miranda' s poetry has been discovered by some poets of the Portuguese language, on both sides of the Atlantic. Here are presented the discovery of two poets: Carlito Azevedo, in the nineties, in Brazil, and Alexandre O'Neill, in the seventies, in Portugal. Both poets seem to have discovered the newness of Sá de Miranda in the writings of brothers Campos. 